\title{
Concurrent chemoradiotherapy in adjuvant treatment of breast
}

\section{cancer}

\author{
Nabil Ismaili*1, Nawfel Mellas ${ }^{1}$, Ouafae Masbah ${ }^{2}$, Sanaa Elmajjaoui ${ }^{2}$, \\ Samia Arifi 1,3, Imane Bekkouch ${ }^{2}$, Samir Ahid ${ }^{4,5}$, Zakaria Bazid6, \\ Mohammed Adnane Tazi ${ }^{7}$, Abdelouahed Erraki ${ }^{7}$, Omar El Mesbahi ${ }^{3}$, \\ Noureddine Benjaafar ${ }^{2,7}$, Brahim El Khalil El Gueddari², \\ Mohammed Ismaili ${ }^{8}$, Said Afqir ${ }^{9}$ and Hassan Errihani ${ }^{1}$
}

Address: ${ }^{1}$ Department of Medical Oncology, National Institute of Oncology, Rabat, Morocco, ${ }^{2}$ Department of Radiotherapy, National Institute of Oncology, Rabat, Morocco, ${ }^{3}$ Department of Medical Oncology, Hassan II Hospital, Fes, Morocco, ${ }^{4}$ Pharmacology and Toxicology Department, Faculty of Medicine, Rabat, Morocco, ${ }^{5}$ Department of Medical Statistics, Faculty of Medicine, Rabat, Morocco, ${ }^{6}$ Department of Cardiology B, IbnSina Hospital, Rabat, Morocco, ${ }^{7}$ Epidemiology Unit, National Institute of Oncology, Rabat, Morocco, ${ }^{8}$ Department of Microbiology, Moulay Ismail University, Meknes, Morocco and ${ }^{9}$ Department of Medical Oncology, Mohammed I Hospital, Oujda, Morocco

Email: Nabil Ismaili* - ismailinabil@yahoo.fr; Nawfel Mellas - mellasnawfel@yahoo.fr; Ouafae Masbah - masbahouafae1979@yahoo.fr; Sanaa Elmajjaoui - dr_majjaoui@yahoo.fr; Samia Arifi - drsarifi@yahoo.fr; Imane Bekkouch - bekkiman78@yahoo.fr; Samir Ahid - samirahid@yahoo.fr; Zakaria Bazid - bazidzakaria@yahoo.fr; Mohammed Adnane Tazi - matazi5@yahoo.fr;

Abdelouahed Erraki - matazi5@yahoo.fr; Omar El Mesbahi - elmesbahiomar@yahoo.fr; Noureddine Benjaafar - b.elgueddari@medramo.ac.ma; Brahim El Khalil El Gueddari - b.elgueddari@medramo.ac.ma; Mohammed Ismaili - ismailih2000@yahoo.fr;

Said Afqir - saidafqir@hotmail.com; Hassan Errihani - h_errihani@yahoo.fr

* Corresponding author

Published: 7 April 2009

Radiation Oncology 2009, 4:12 doi:10.1186/1748-717X-4-12

This article is available from: http://www.ro-journal.com/content/4/l/I2

(C) 2009 Ismaili et al; licensee BioMed Central Ltd.

This is an Open Access article distributed under the terms of the Creative Commons Attribution License (http://creativecommons.org/licenses/by/2.0), which permits unrestricted use, distribution, and reproduction in any medium, provided the original work is properly cited.
Received: 8 January 2009

Accepted: 7 April 2009

\begin{abstract}
Background: The optimal sequencing of chemotherapy and radiotherapy after breast surgery was largely studied but remains controversial. Concurrent chemo-radiotherapy is a valuable method for adjuvant treatment of breast cancer which is under ongoing research program in our hospital. We are evaluating the feasibility of the concomitant use of chemotherapy retrospectively.

Methods: Two hundred forty four women having breast cancer were investigated in a retrospective study. All patients were either treated by radical surgery or breast conservative surgery. The study compares two adjuvant treatments associating concomitant chemotherapy and radiotherapy. In the first group (group A) the patients were treated by chemotherapy and radiotherapy in concomitant way using anthracycline $(n=110)$. In the second group (group B) the patients were treated by chemotherapy and radiotherapy in concomitant way using CMF treatment $(n=134)$. Chemotherapy was administered in six cycles, one each 3 weeks. Radiotherapy delivered a radiation dose of $50 \mathrm{~Gy}$ on the whole breast (or on the external wall) and/or on the lymphatic region. The Kaplan-Meier method was used to estimate the rates of disease free survival, locoregional recurrence-free survival and overall survival. The Pearson $\mathrm{Khi}^{2}$ test was used to analyse the homogeneity between the two groups. The log-rank test was used to evaluate the differences between the two groups $A$ and $B$.
\end{abstract}


Results: After 76.4 months median follow-up (65.3 months mean follow up), only one patient relapsed to loco-regional breast cancer when the treatment was based on anthracycline. However, 8 patients relapsed to loco-regional breast cancer when the treatment was based on CMF. In the anthracycline group, the disease free survival after 5 years, was $80.4 \%$ compared to $76.4 \%$ in the CMF group (Log-rank test: $p=0.136$ ). The overall survival after 5 years was $82.5 \%$ and $81.1 \%$ in the anthracycline and CMF groups respectively (Log-rank test: $p=0.428$ ). The loco-regional free survival at 5 years was equal to $98.6 \%$ in group $A$ and $94 \%$ in group B (Log-rank test: $p=0,033$ ). The rate of grade II and grade III anaemia was $13.9 \%$ and $6.7 \%$ in anthracycline group and CMF group respectively $\left(\mathrm{Khi}^{2}\right.$-test: $\left.\mathrm{P}=0.009\right)$. The rate of grade II and grade III skin dermatitis toxicity was $4.5 \%$ in the group $A$ and $0 \%$ in the group $B($ Khi²-test: $p=0.013)$.

Conclusion: From the 5 years retrospective investigation we showed similar disease free survival and overall survival in the two concurrent chemo-radiotherapy treatments based on anthracycline and CMF. However in the loco-regional breast cancer the treatment based on anthracycline was significantly better than that of the treatment based on CMF. There was more haematological and skin dermatitis toxicity in the anthracycline group.

\section{Background}

In the case of early breast cancer and after radical mastectomy or conservative surgery, adjuvant radiotherapy is mandatory for diminishing the risk of recurrence [1-9]. Adjuvant chemotherapy is equally mandatory for diminishing metastasis recurrences [10-12]. However, the optimal sequence of treatments is not clearly defined and remains controversial. Several trials have shown that the incidence of spared metastasis is more important in the case of delay of chemotherapy, and local's recurrences are more frequents in the case of delay of radiotherapy $[13,14]$. Current standard treatment sequence is chemotherapy followed by radiotherapy. We are trying by this retrospective study to document and support the feasibility and efficiency of concurrent chemo-radiotherapy.

\section{Methods}

\section{Patient selection}

From January 2001 to December 2002, a large group of 244 patients with early breast carcinoma were selected at the National Institute of Oncology in Rabat, for investigation during treatment and up to now follow up. The patients were divided in two groups on the basis of chemotherapy treatment. In group A the treatment was based on anthracycline and in group B the treatment was based on CMF. Eighty four percent of the investigated cases ( $81 \%$ in group A and $86.5 \%$ in group B; Pearson-Khi ${ }^{2}$ test: $p=0.23$ ) had radical surgery [201 received Patey mastectomy and 4 received Halsted mastectomy ( 2 in group A and 2 in group $\mathrm{B})]$ and the remaining $16 \%$ of the cases (19\% in group A and $13.5 \%$ in group B; Pearson-Khi ${ }^{2}$ test: $p=0.23$ ) had breast conservative surgery [34 received tumorectomy and 5 received quadrentectomy ( 3 in group A and 2 in group B)]. All the 244 patients underwent concurrent adjuvant chemo-radiotherapy. In the concurrent chemo-radiotherapy both chemotherapy and radiotherapy were delivered at the same time. The median number of chemotherapy cycles delivered with radiotherapy was 2 (ranging from 1 to 5). Eighty percent of the patients (195 patients) received 2 or more chemotherapy cycles with concomitant radiotherapy. Patient medical records were retrospectively analysed and the following parameters were considered: demographic data, clinical stages, histological findings, treatment and outcome. Radiological, pathological and surgical reports were reviewed to determine the stage of the disease at the time of surgery by using the 2002 TNM classification for breast cancer [15]. The diagnostic instrumental examinations used to stage patients were: chest radiograph performed in all patients; abdominal ultrasound performed in all patients; and bone scan performed in only $16 \%$ of the patients (39 patients).

\section{Treatment plan}

Data about treatment, notably surgery, chemotherapy and radiotherapy, were extracted from patient medical records. The date and site of recurrence and, if applicable, the date of death were also considered. The first group A of 110 patients was treated with anthracycline based protocol and the second group B of 134 patients was treated with CMF protocol. Additional file 1 and Diagram 1 summarizes the therapeutic strategy. According to the protocol followed at our institute, $95.5 \%$ of the patients received a radiotherapy treatment delivered to the whole breast or to thoracic wall (99.1\% in group A and $92.5 \%$ in group B); in addition, the same $95.5 \%$ of the patients received a radiotherapy treatment delivered to the regional lymph nodes. The $4.5 \%$ of patients left received a radiotherapy treatment delivered to the whole breast or to the thoracic wall, in addition to a radiotherapy treatment delivered in the regional lymph nodes. All patients were treated with external beam radiotherapy using tangential fields of Co60-gamma-Ray. The total delivered dose was $50 \mathrm{~Gy}$, divided as 2-Gy daily fractions. The complementary treat- 
ment was given by electrons or by breast brachytherapy. The total complementary dose ranged from 10 to $20 \mathrm{~Gy}$ for 10 patients. Chemotherapy consisted of: a- intravenous CMF (cyclophosphamide $500 \mathrm{mg} / \mathrm{m}^{2}$, methotrexate $60 \mathrm{mg} / \mathrm{m}^{2}$, and 5 -fluorouracil $500 \mathrm{mg} / \mathrm{m}^{2}$ ) on day 1 , repeated every 21 days for six courses for 134 patients, bintravenous AC60 (doxorubicin $60 \mathrm{mg} / \mathrm{m}^{2}$ and cyclophosphamide $600 \mathrm{mg} / \mathrm{m}^{2}$ ) on day 1, repeated every 21 days for six courses for 57 patients, c- intravenous FEC75 (5-fluorouracile $500 \mathrm{mg} / \mathrm{m}^{2}$, epirubicin $75 \mathrm{mg} / \mathrm{m}^{2}$, and cyclophosphamide $500 \mathrm{mg} / \mathrm{m}^{2}$ ) on day 1 , repeated every 21 days for six courses for 23 patients and d-intravenous FAC50 (5-fluorouracile $500 \mathrm{mg} / \mathrm{m}^{2}$, doxorubicin $50 \mathrm{mg}$ / $\mathrm{m}^{2}$, and cyclophosphamide $500 \mathrm{mg} / \mathrm{m}^{2}$ ) on day 1 , repeated every 21 days for six courses for 20 patients, and e- sequential treatment, repeated every 21 days for six courses for 10 patients (table 1, additional file 1 and diagram 1). We retrospectively compared toxicity, disease free survival and overall survival between two therapeutic groups A and B and between the sub-groups within A and B.

\section{Statistical analysis}

Overall survival (OS) and disease free survival (DFS) were analyzed statistically in all patients. Time to recurrence was calculated from the date of surgery to the date of first documented relapse or to the date of last follow up. Overall survival was calculated from the date of histological diagnosis (Fine Needle Aspiration, biopsy, or surgery) to the date of death or to the date of last follow up. The Kaplan-Meier method was used to estimate the rates of DFS, loco-regional recurrence-free survival (LRFS) and OS. The log-rank test was used to evaluate the differences between the two groups $\mathrm{A}$ and $\mathrm{B}$. The distribution homogeneity was analyzed with the Pearson chi $^{2}$-test for both groups and for all subgroups. The distribution of patient charac-

Table I: Sequential treatments

\begin{tabular}{cc}
\hline Protocol & Number of patients \\
\hline $2 \mathrm{AC} 60 \rightarrow 4 \mathrm{CMF}^{*}$ & 2 \\
$2 \mathrm{FAC} 50 \rightarrow 4 \mathrm{CMF}^{*}$ & $\mathrm{I}$ \\
$6 \mathrm{CMF} * \rightarrow 4 \mathrm{AT}^{*}$ & $\mathrm{I}$ \\
$3 \mathrm{FAC} 50 \rightarrow 3 \mathrm{CMF} *$ & 2 \\
$4 \mathrm{CMF} \rightarrow 2 \mathrm{FEC7}^{*}$ & $\mathrm{I}$ \\
$2 \mathrm{AC} 60 \rightarrow 4 \mathrm{CMF}^{*}$ & $\mathrm{I}$ \\
$2 \mathrm{CMF}^{*} \rightarrow 4 \mathrm{AC}$ & $\mathrm{I}$ \\
$4 \mathrm{AC}^{*} \rightarrow 2 \mathrm{CMF}$ & $\mathrm{I}$
\end{tabular}

$*=$ regimen delivered in concomitant with radiotherapy; $\mathrm{CMF}=$ cyclophosphamide $500 \mathrm{mg} / \mathrm{m}^{2}$, methotrexate $60 \mathrm{mg} / \mathrm{m}^{2}$, and 5fluorouracil $500 \mathrm{mg} / \mathrm{m}^{2} ; \mathrm{AC} 60=$ doxorubicin $60 \mathrm{mg}$ and cyclophosphamide $600 \mathrm{mg} / \mathrm{m}^{2} ; \mathrm{FEC75}=$-fluorouracile $500 \mathrm{mg} / \mathrm{m}^{2}$, epirubicin $75 \mathrm{mg} / \mathrm{m}^{2}$, and cyclophosphamide $500 \mathrm{mg} / \mathrm{m}^{2} ; \mathrm{FAC} 50=5-$ fluorouracile $500 \mathrm{mg} / \mathrm{m}^{2}$, doxorubicin $50 \mathrm{mg} / \mathrm{m}^{2}$, and cyclophosphamide $500 \mathrm{mg} / \mathrm{m}^{2} ;$ AT = doxorubicin $50 \mathrm{mg} / \mathrm{m}^{2}$ and docetaxel $75 \mathrm{mg} / \mathrm{m}^{2}$ teristics was partly imbalanced. The influence on survival of several prognostic factors (age, lymph node involvement, tumour volume, tumour grade, receptor status, and treatment regime) was analyzed by Cox regression. Statistical evaluation was carried out using SPSS 13.0 statistical software.

\section{Results \\ Patient characteristics}

Between January 2001 and December 2002, 244 women were retrospectively evaluated. One hundred ten patients received concurrent chemo-radiotherapy with anthracycline based regimen and 134 patients received concurrent chemo-radiotherapy with CMF based regimen. The demographic, clinical, pathologic, and therapeutic characteristics of the two groups of patients were summarized in table 2. After the analysis of homogeneity characteristics of the two groups we found more women aged less than 40 years $\left(\mathrm{Khi}^{2}\right.$-test: $\left.\mathrm{p}=0.039\right)$ and more lymph node involvement (Khi²-test: $\mathrm{p}=0.001)$ in the anthracycline group than in group B (table 2). The progesterone receptor status was the only statistically different subgroup from the three most important anthracycline sub-groups (Table 3). The homogeneity between the groups of patients managed either with mastectomy or breast conservative therapy (BCT) was also studied and summarized in table 4. For all patients, the mean delay of chemotherapy after surgery was 6.9 weeks (ranging from 0.7 to 37.9 weeks). And the mean delay of radiotherapy after surgery was 12.4 weeks (ranging from 2.4 to 53.3 weeks). In the two groups A and B respectively, $96.4 \%$ and $97.7 \%$ of the patients received the 6 courses of chemotherapy. All patients in the two groups received $100 \%$ of the planned radiotherapy dose.

\section{Treatment compliance}

Analysis of haematological toxicity showed that the rate of grade III-IV neutropenia was $9.3 \%$ vs $6.2 \%$ in group A and $\mathrm{B}$ respectively ( $\mathrm{Khi}^{2}$-test: $\mathrm{p}=0.4$ ). The rate of grade II-III anaemia was $13.9 \%$ vs $6.7 \%$ in anthracycline group and CMF group respectively ( $\mathrm{Khi}^{2}$-test: $\left.\mathrm{p}=0.009\right)$ (Table 5$)$. There was no cardiac toxicity that was clinically detectable in the two arms. The left ventricular fraction ejection (LVFE) was evaluated in only 7 patients ( 2 patients in the anthracycline group and 5 in the CMF group) and was normal (LVFE ranged between $63 \%$ and $87 \%$ ). This constitutes the main limitation of our retrospective study. The second limitation was the skin dermatitis toxicity events which were noted in only few cases when the patients presented high toxicity grade. Therefore, we showed that $4.5 \%$ of the patients treated with anthracycline regimen had poor cosmetic results (grade II-III skin dermatitis toxicity), but in no patient of the group B the skin dermatitis toxicity was noted $\left(\mathrm{Khi}^{2}\right.$-test: $\left.\mathrm{p}=0.013\right)$. The third limitation was the lake of pulmonary toxicity follow up in our 
Table 2: Demographic, clinical, histological, molecular and treatment characteristics of patients and analysis of groups homogeneity (test Pearson Khi²)

\begin{tabular}{|c|c|c|c|}
\hline $\begin{array}{l}\text { Characteristic } \\
\text { Age }\end{array}$ & Group A [n = I I 0$]$ No (\%) & Group B [n = 134] No (\%) & p value \\
\hline$<40$ & $31(28.2 \%)$ & $23(17.2 \%)$ & 0.039 \\
\hline$\geq 40$ & 79 (7I.8\%) & $111(82.8 \%)$ & \\
\hline \multicolumn{4}{|l|}{ Menopausal status } \\
\hline No & 75 (72.8\%) & 77 (62.1\%) & 0.087 \\
\hline Yes & $28(27.2 \%)$ & $47(37.9 \%)$ & \\
\hline \multicolumn{4}{|l|}{ Side } \\
\hline Right & $48(43.6 \%)$ & 71 (53\%) & 0.146 \\
\hline Left & $62(56.4 \%)$ & $63(47 \%)$ & \\
\hline \multicolumn{4}{|l|}{ Surgery } \\
\hline Mastectomy (Patey or Halsted) & 89 (80.9\%) & $116(86.6 \%)$ & 0.23 \\
\hline Conservative & $21(19.1 \%)$ & $18(13.4 \%)$ & \\
\hline \multicolumn{4}{|l|}{ Histology } \\
\hline DIC & $99(94,3 \%)$ & $120(90,9 \%)$ & 0.33 \\
\hline LIC & $6(5.7 \%)$ & $12(9.1 \%)$ & \\
\hline \multicolumn{4}{|l|}{ SBR } \\
\hline I & $6(5.7 \%)$ & II (8.5\%) & 0.567 \\
\hline II & $69(65.1 \%)$ & $87(66.9 \%)$ & \\
\hline III & 31 (29.2\%) & $32(24.6 \%)$ & \\
\hline \multicolumn{4}{|l|}{ Hormonal receptors } \\
\hline \multicolumn{4}{|l|}{ ER } \\
\hline Positive & 77 (72\%) & 97 (73.5\%) & 0.793 \\
\hline Negative & $30(28 \%)$ & $35(26.5 \%)$ & \\
\hline \multicolumn{4}{|l|}{ PR } \\
\hline Positive & 61 (57.5\%) & $82(62.1 \%)$ & 0.474 \\
\hline Negative & 45 (42.5\%) & $50(37.9 \%)$ & \\
\hline \multicolumn{4}{|l|}{ Tumour } \\
\hline PTI & $16(14.7 \%)$ & $19(14.5 \%)$ & 0.732 \\
\hline PT2 & $62(56.9 \%)$ & $76(58 \%)$ & \\
\hline PT3 & $28(25.7 \%)$ & $29(22.1 \%)$ & \\
\hline PT4 & $3(2.8 \%)$ & $7(5.3 \%)$ & \\
\hline \multicolumn{4}{|l|}{ pN, axillary } \\
\hline pNo & 20 (18.2\%) & 40 (29.9\%) & 0.001 \\
\hline $\mathrm{pNI}$ & $30(27.3 \%)$ & $42(31.3 \%)$ & \\
\hline pN2 & $31(28.2 \%)$ & $42(31.3 \%)$ & \\
\hline $\mathrm{pN} 3$ & $29(26.4 \%)$ & $10(7.5 \%)$ & \\
\hline \multicolumn{4}{|l|}{ Breast/thoracic wall irradiation } \\
\hline Yes & $109(99.1 \%)$ & $124(92.5 \%)$ & 0.014 \\
\hline No & I (0.9\%) & $10(7.5 \%)$ & \\
\hline \multicolumn{4}{|c|}{ Prophylactic supraclavicular fossa radiotherapy } \\
\hline Yes & $104(94.5 \%)$ & $127(94.8 \%)$ & 0.936 \\
\hline No & $6(5.5 \%)$ & $7(5.2 \%)$ & \\
\hline \multicolumn{4}{|l|}{ Internal mammary radiotherapy } \\
\hline Yes & $105(95.5 \%)$ & $128(95.5 \%)$ & 0.98 \\
\hline No & $5(4.5 \%)$ & $6(4.5 \%)$ & \\
\hline
\end{tabular}


Table 2: Demographic, clinical, histological, molecular and treatment characteristics of patients and analysis of groups homogeneity (test Pearson Khi²) (Continued)

\begin{tabular}{lll}
\hline Axillary radiotherapy & & $31(23.1 \%)$ \\
Yes & $18(16.4 \%)$ & $103(76.9 \%)$ \\
No & $92(83.6 \%)$ & 0.189 \\
\hline
\end{tabular}

SBR = Scarf-Bloom-Richardson; $\mathrm{DIC}=$ ductal invasive carcinoma; $\mathrm{LIC}=$ lobular invasive carcinoma; $\mathrm{ER}=$ estrogen receptor; $\mathrm{PR}=$ progesterone receptor

data base. Nevertheless, only 2 patients in the AC60 subgroups showed dry cough.

\section{Outcomes}

After 76.4 months median follow-up and 65.3 months mean follow up (ranging between 9.6 to 106 months), only one patient developed loco-regional relapse when the treatment was based on anthracycline. In contrast, 8 patients relapsed to loco- regional breast cancer in the CMF group. The 5 years loco-regional recurrence free survival rate was equal to $98.6 \%$ in group A $v$ s $94 \%$ in group $\mathrm{B}$; Log-rank test: $\mathrm{p}=0.033$ (Figure 1 ). The 5 years rate of DFS was $80.4 \%$ in group A vs $76.4 \%$ in group B; Log-rank test: $\mathrm{p}=0.136$ (Figure 2 ). The 5 years overall survival rate was $82.5 \%$ in group A vs $81.1 \%$ in group B; Log-rank test: $\mathrm{p}=0.428$ (Figure 3 ). Using univariate analysis, we found that the only prognosis factor influencing survival was the lymph node involvement status $(\mathrm{p}=0.007)$ (Cox regression) (table 6).

Analysis of the data showed no difference in survival between the 3 anthracycline cycles regimen: AC60, FEC75 and FAC 50; Log-rank test: $\mathrm{p}=0.982$ (Figure 4). And there was no difference in disease free survival and overall survival between the patients treated by mastectomy or breast conservative therapy (DFS: $\mathrm{p}=0.288$; OS: $\mathrm{p}=0.173$ ) (Figure 5 and 6).

\section{Discussion}

Radiotherapy and chemotherapy after surgery are mandatory in the multidisciplinary management of early-stage breast cancer. Even if the optimal sequencing of theses treatments was largely studied during the last two decades, they remain controversial. Several retrospective studies have suggested an increase in local recurrence rates when radiotherapy was delivered after the end of chemotherapy treatment $[13,14]$. Hartsell et al showed that delays in the irradiation treatment were associated with increased risk of relapse in the breast cancer and recommended that radiotherapy treatment should be delivered within 120 days after breast surgery. Other authors showed that a delay in the initiation of RT for a period of 6 months or greater from diagnosis resulted in a higher local failure rate with an increased rate of distant metastases and a decreased overall survival rate. The Joint Centre for Radiation Therapy Trial (JCRT) confirmed theses results (rate of local recurrences was $5 \%$ vs $14 \%$ when radiotherapy was delayed) and suggested that radiotherapy should be delivered before chemotherapy [16]. However, other retrospective studies have suggested an increased rate of distant recurrences when RT was delivered before chemotherapy [17-20].

The current standard of care of early breast cancer was the surgery followed by chemotherapy followed by radiotherapy. Concurrent chemo-radiotherapy is a valuable method because of two advantages: 1. delivering the booths treatment in same time without any delay of chemotherapy or radiotherapy; 2 . adjunction of chemotherapy to radiotherapy might produce a biological synergy effect that can increase the efficacy of the treatment [21]. Chemotherapy treatments based on liposomal doxorubicin, paclitaxel and vinorelbine, with concomitant RT in non operable and recurrent disease, were found to be of good efficacy and tolerability [21,22]. Reirradiation with concomitant chemotherapy was shown to have positive effect $[21,23]$.

The promising results of concurrent chemo-radiotherapy showed in previous studies leaded us to investigate the efficacy and tolerability of this treatment in early breast cancer.

The objective of our contribution was to document and support the feasibility of concomitant treatment used at the national institute of oncology in Rabat and to confront our results to the results of 3 randomised studies published previously. Our work concerned the study of a data base of 244 patients treated by radical mastectomy ( $84 \%)$ or by BCT (16\%) to compare efficacy and tolerability of two concomitant protocols: the first with anthracycline based regimen and the second with CMF regimen. After 76.4 months median follow-up and 65.3 months mean follow up (ranging between 9.6 to 106 months) we found no statistical difference in the DFS and the OS between the two therapeutic groups $A$ and $B$. 5 years rate of DFS was $80.4 \%$ in group A vs $76.4 \%$ in group B; Logrank test: $\mathrm{p}=0.136$ and the 5 year overall survival rate was $82.5 \%$ in group A vs $81.1 \%$ in group B; Log-rank test: $\mathrm{p}=$ 0.428 . However, to better explain these results and demonstrate the beneficial effect of one of the two protocols (anthracycline regimen and CMF regimen) over the other, the homogeneity of two groups was analysed. This analysis showed the presence of poorer prognosis factors in the 
Table 3: Analysis of anthracycline sub-groups (AC60, FEC75 and FAC50) homogeneity (test Pearson Khi²)

\begin{tabular}{|c|c|c|c|c|}
\hline Patients characteristics & Group FEC75 $[n=23]$ No (\%) & Group FAC50 $[n=20]$ No (\%) & Group AC60 $[n=57]$ No (\%) & p value \\
\hline \multicolumn{5}{|l|}{ Age } \\
\hline$<40$ & $8(34.8 \%)$ & 7 (35\%) & $14(24.6 \%)$ & 0.53 \\
\hline$\geq 40$ & $15(65.2 \%)$ & $13(65 \%)$ & $43(75.4 \%)$ & \\
\hline \multicolumn{5}{|l|}{ Menopausal status } \\
\hline No & 20 (90.9\%) & 14 (77.8\%) & $35(66 \%)$ & 0.075 \\
\hline Yes & $2(9.1 \%)$ & $4(22.2 \%)$ & $18(34 \%)$ & \\
\hline \multicolumn{5}{|l|}{ Side } \\
\hline Right & 14 (60.9\%) & $7(35 \%)$ & $24(42.1 \%)$ & 0.188 \\
\hline Left & $9(39.1 \%)$ & $13(65 \%)$ & $33(57.9 \%)$ & \\
\hline \multicolumn{5}{|l|}{ Surgery } \\
\hline Mastectomy & $5(21.7 \%)$ & $5(25 \%)$ & $8(14 \%)$ & 0.457 \\
\hline Conservative & $18(78.3 \%)$ & $15(75 \%)$ & $49(86 \%)$ & \\
\hline \multicolumn{5}{|l|}{ Histology } \\
\hline $\mathrm{CCl}$ & $20(95.2 \%)$ & $19(95 \%)$ & $52(94.5 \%)$ & 0.992 \\
\hline CLI & $\mathrm{I}(4.8 \%)$ & I (5\%) & $3(5.5 \%)$ & \\
\hline \multicolumn{5}{|l|}{ SBR } \\
\hline 1 & 0 & I (5\%) & $4(7.1 \%)$ & 0.31 \\
\hline II & 14 (70\%) & $10(50 \%)$ & $39(69.6 \%)$ & \\
\hline III & $6(30 \%)$ & $9(45 \%)$ & $13(23.2 \%)$ & \\
\hline \multicolumn{5}{|l|}{ Hormonal receptors } \\
\hline \multicolumn{5}{|l|}{ ER } \\
\hline Positive & $18(81.8 \%)$ & II (55\%) & $42(76.4 \%)$ & 0.106 \\
\hline Negative & $4(18.2 \%)$ & $9(45 \%)$ & $13(23.6 \%)$ & \\
\hline \multicolumn{5}{|l|}{ PR } \\
\hline Positive & 17 (77.3\%) & $7(35 \%)$ & $31(57.4 \%)$ & 0.022 \\
\hline Negative & $5(22.7 \%)$ & $13(65 \%)$ & $23(42.6 \%)$ & \\
\hline \multicolumn{5}{|l|}{ Tumour } \\
\hline PTI & $6(26.1 \%)$ & I (5\%) & $9(16.1 \%)$ & 0.514 \\
\hline PT2 & $10(43.5 \%)$ & $13(65 \%)$ & $32(57.1 \%)$ & \\
\hline PT3 & $7(30.4 \%)$ & $5(25 \%)$ & $13(23.2 \%)$ & \\
\hline PT4 & 0 & I (5\%) & $2(3.6 \%)$ & \\
\hline \multicolumn{5}{|l|}{ pN, axillary } \\
\hline pNO & $6(26.1 \%)$ & $3(15 \%)$ & $9(15.8 \%)$ & 0.807 \\
\hline $\mathrm{pNI}$ & $4(17.4 \%)$ & $4(20 \%)$ & $15(26.3 \%)$ & \\
\hline $\mathrm{pN} 2$ & $7(30.4 \%)$ & $5(25 \%)$ & $18(31.6 \% \%)$ & \\
\hline pN3 & $6(26.1 \%)$ & $8(40 \%)$ & $15(26.3 \% \%)$ & \\
\hline
\end{tabular}

FEC75 = 5-fluorouracile $500 \mathrm{mg} / \mathrm{m}^{2}$, epirubicin $75 \mathrm{mg} / \mathrm{m}^{2}$, and cyclophosphamide $500 \mathrm{mg} / \mathrm{m}^{2} ; \mathrm{FAC} 50=5$-fluorouracile $500 \mathrm{mg} / \mathrm{m}^{2}$, doxorubicin 50 $\mathrm{mg} / \mathrm{m}^{2}$, and cyclophosphamide $500 \mathrm{mg} / \mathrm{m}^{2} ; A C 60=$ doxorubicin $60 \mathrm{mg}$ and cyclophosphamide $600 \mathrm{mg} / \mathrm{m}^{2} ; \mathrm{SBR}=$ Scarf-Bloom-Richardson; DIC = ductal invasive carcinoma; $\mathrm{LIC}=$ lobular invasive carcinoma; $E R=$ estrogen receptor; $P R=$ progesterone receptor

anthracycline group (younger women and more lymph node involvement). In fact, there were significantly younger women (Pearson-Khi ${ }^{2}$ test: $\mathrm{p}=0.039$ ) and more positive lymph nodes (Pearson-Khi² test: $\mathrm{p}=0.001$ ) in the anthracycline group. In addition, we showed significantly better local control in the anthracycline group; Log-rank test: $\mathrm{p}=0.033$. Overall, the patients in the two groups showed a very good loco-regional control.

In Europe, three recent randomised phase III trials were conducted to compare the sequential protocol (chemotherapy first) to the concomitant protocol: 1- in the first 
Table 4: Analysis of demographic, clinical, histological, molecular and therapeutic characteristics of patients treated with mastectomy and breast conservative therapy (BCT) (test Pearson Khi2)

\begin{tabular}{|c|c|c|c|}
\hline Patients characteristics & Mastectomy $[n=205]$ No (\%) & BCT $[n=39]$ No (\%) & p value \\
\hline \multicolumn{4}{|l|}{ Age } \\
\hline$<40$ & $48(23.4 \%)$ & $6(15.4 \%)$ & 0.268 \\
\hline$\geq 40$ & $157(76.6 \%)$ & $33(84.6 \%)$ & \\
\hline \multicolumn{4}{|l|}{ Menopausal status } \\
\hline No & $129(67.5 \%)$ & $23(63.9 \%)$ & 0.669 \\
\hline Yes & $62(32.5 \%)$ & $13(36.1 \%)$ & \\
\hline \multicolumn{4}{|l|}{ Side } \\
\hline Right & $48(43.6 \%)$ & $71(53 \%)$ & 0.146 \\
\hline Left & $62(56.4 \%)$ & $63(47 \%)$ & \\
\hline \multicolumn{4}{|l|}{ Histology } \\
\hline DIC & $183(91.1 \%)$ & $36(100 \%)$ & 0.062 \\
\hline LIC & $18(9 \%)$ & 0 & \\
\hline \multicolumn{4}{|l|}{ SBR } \\
\hline 1 & $13(6.6 \%)$ & $4(10.5 \%)$ & 0.53 \\
\hline ॥ & $130(65.7 \%)$ & $26(68.4 \%)$ & \\
\hline III & $55(27.8 \%)$ & $8(21.1 \%)$ & \\
\hline \multicolumn{4}{|l|}{ Hormone receptors } \\
\hline \multicolumn{4}{|l|}{ ER } \\
\hline Positive & $120(60.3 \%)$ & $28(71.8 \%)$ & 0.877 \\
\hline Negative & $79(39.7 \%)$ & II (28.2\%) & \\
\hline \multicolumn{4}{|l|}{ PR } \\
\hline Positive & 61 (57.5\%) & $23(59 \%)$ & 0.877 \\
\hline Negative & 45 (42.5\%) & $16(41 \%)$ & \\
\hline \multicolumn{4}{|l|}{ Tumour } \\
\hline PTI & $25(12.4 \%)$ & $10(25.6 \%)$ & 0.003 \\
\hline PT2 & III (55.2\%) & 27 (69.2\%) & \\
\hline PT3 & $55(27.4 \%)$ & $2(5.1 \%)$ & \\
\hline pT4 & $10(5 \%)$ & 0 & \\
\hline \multicolumn{4}{|l|}{ pN, axillary } \\
\hline pNO & 49 (23.9\%) & II (28.2\%) & 0.285 \\
\hline $\mathrm{pNI}$ & $57(27.8 \%)$ & $15(38.5 \%)$ & \\
\hline $\mathrm{pN} 2$ & $63(30.7 \%)$ & $10(25.6 \%)$ & \\
\hline $\mathrm{pN} 3$ & $36(17.6 \%)$ & $3(7.7 \%)$ & \\
\hline \multicolumn{4}{|l|}{ Protocol } \\
\hline Anthracycline & $89(43.4 \%)$ & $21(53.8 \%)$ & 0.23 \\
\hline CMF & $116(56.6 \%)$ & $18(46.2 \%)$ & \\
\hline \multicolumn{4}{|c|}{ Breast/thoracic wall irradiation } \\
\hline Yes & $194(94.6 \%)$ & $39(100 \%)$ & 0.139 \\
\hline No & II (5.4\%) & 0 & \\
\hline \multicolumn{4}{|c|}{ Prophylactic supraclavicular fossa radiotherapy } \\
\hline Yes & $193(94.1 \%)$ & $38(97.4 \%)$ & 0.402 \\
\hline No & $12(5.9 \%)$ & $\mathrm{I}(2.6 \%)$ & \\
\hline \multicolumn{4}{|c|}{ Internal mammary radiotherapy } \\
\hline Yes & $195(94.1 \%)$ & $38(97.4 \%)$ & 0.523 \\
\hline No & $10(5.9 \%)$ & $\mathrm{I}(2.6 \%)$ & \\
\hline \multicolumn{4}{|l|}{ Axillary radiotherapy } \\
\hline Yes & $42(20.5 \%)$ & $7(17.9 \%)$ & 0.717 \\
\hline No & $163(79.5 \%)$ & $32(82.1 \%)$ & \\
\hline
\end{tabular}


trial, 716 early breast cancers patients were treated by BCT and randomised into tow groups (ACROSEIN study) [24]. In the first group, the patients were treated by the FNC protocol (5-fluoro-uracil $500 \mathrm{mg} / \mathrm{m} 2$, mitoxantrone 12 $\mathrm{mg} / \mathrm{m}^{2}$ and cyclophosphamide $500 \mathrm{mg} / \mathrm{m}^{2}$ ) with concomitant radiotherapy. In the second group, the patients were treated by the FNC protocol followed by radiotherapy. The results showed no significant difference in both treatments for the 5-years DFS, LRFS, metastatic free survival, and OS. The two other studies $[25,26]$ compared concurrent and sequential chemotherapy and radiotherapy after surgery for a reduced number of patients. In Italy, Arcangely et al [25] followed 206 patients that were randomly assigned to concurrent or sequential treatments. The two protocols were performed after quadrantectomy and axillary dissection for breast cancer with adjuvant chemotherapy (cyclophosphamide, methotrexate, and fluorouracil [CMF]). No significant differences were found in 5-years breast recurrence-free, metastasisfree, disease-free, and overall survival for the two groups of patients. In the third trial, Rouessé et al [26] followed 638 patients with prior breast surgery and positive axillary dissection (from which 416 were breast conservative surgery) and were randomly assigned to receive concomitant radiotherapy and chemotherapy (FNC protocol) or chemotherapy (fluorouracil, epirubicin, and cyclophosphamide protocol) followed by RT. No differences in 5-years disease-free and overall survival were observed in the two treatment groups. Nevertheless, in the ACROSEIN study the authors identified a significant decrease in the risk of loco-regional recurrence by $39 \%$ with concurrent radiotherapy and chemotherapy for node-positive patients. Rouessé et al [26] showed that concurrent treatment has a significantly better locoregional control in node-positive

Table 5: Haematological toxicity

\begin{tabular}{llll}
\hline $\begin{array}{l}\text { Toxicity } \\
\text { Anemia }\end{array}$ & Group A No (\%) & Group B No (\%) & p value \\
\hline Grade I & $35(32.4 \%)$ & $25(19.2 \%)$ & 0.009 \\
Grade II & $13(12 \%)$ & $7(5.4 \%)$ & \\
Grade III & $2(1.9 \%)$ & $1(1.3 \%)$ & \\
Grade IV & 0 & & \\
Neutropenia & & & \\
\hline Grade I & $13(12 \%)$ & $15(11.5 \%)$ & 0.4 \\
Grade II & $27(25 \%)$ & $26(20 \%)$ & \\
Grade III & $8(7.4 \%)$ & $8(6.2 \%)$ & \\
Grade IV & $2(1.9 \%)$ & 0 & 0.34 I \\
Thrombopenia & & & \\
\hline Grade I & $2(1.9 \%)$ & $2(1.5 \%)$ & \\
Grade II & $2(1.9 \%)$ & 0 & \\
Grade III & I (0.9\%) & 0 & \\
Grade IV & 0 & $1(0.8 \%)$ & \\
\hline
\end{tabular}

breast cancer after conservative surgery. In our study we found very good loco-regional control of the disease with only one loco-regional recurrence in the anthracycline goup and 8 in CMF group $(p=0.033)$. The main limitation of the tree European trials was the use of CMF protocol and FNC protocol without the use of anthracyclines and taxanes in the chemotherapy treatment. To our knowledge, our study is the first investigation which tests the efficacy and tolerability of the concomitant association of anthracycline regimen with radiotherapy. Our results confirm the superiority of this treatment to CMF regimen in term of local control. Anthracycline administered after RT showed a high incidence of severe skin dermatitis and oesophagitis, as reported by Recht et al [17]. In contrary to mitoxantrone, the anthracycline chemotherapy induces free-radical production that may potentiate normal tissue reactions. In ACROSEIN study, acute loco regional toxicities were moderate in the concomitant arm. Rouessé et al [26] presented more frequent grade 2 skin toxicities in the concomitant arm, and more sub clinical left ventricular ejection fraction events at 1 year $(\mathrm{p}=$ 0.02 ). In our study we showed more haematological toxicity when the treatment is based on anthracycline with significantly more grade II-III anaemia $(13.9 \%$ vs $6.7 \%$; $\mathrm{Khi}^{2}$ test $\left.\mathrm{p}=0.009\right)$. Grade III-IV neutropenia $(9.3 \%$ vs $6.2 \%)$ and thrombopenia ( $0.9 \%$ vs $0.8 \%)$ were equally more frequent in anthracycline group but the differences were not significant. The lack of cardiac toxicity evaluation constitutes the main limitation of our retrospective study. Other limitations were the lack of skin and pulmonary toxicities evaluations. However, we can conclude that there was no clinical cardiac toxicity in the two groups and only $4.5 \%$ of the patients had poor cosmetic results in the anthracycline group versus $0 \%$ in the $\mathrm{CMF}$ group (Khi ${ }^{2}$ test: $\mathrm{p}=0.039$ ).

\section{Conclusion}

Concurrent chemo-radiotherapy is a valuable treatment protocol which shows promising results with good tolerability in non operable and recurrent breast cancer.

In early breast cancer, the previous published studies failed to show superiority of concurrent chemo-radiotherapy in term of survival.

From the present five years retrospective investigation we showed a similarity of the concurrent chemo-radiotherapy treatment results in DFS and OS and we identified a very good loco-regional control when this treatment was based on anthracycline.

Waiting for the results of ongoing research the standard of care is the use adjuvant chemotherapy prior to radiotherapy. 


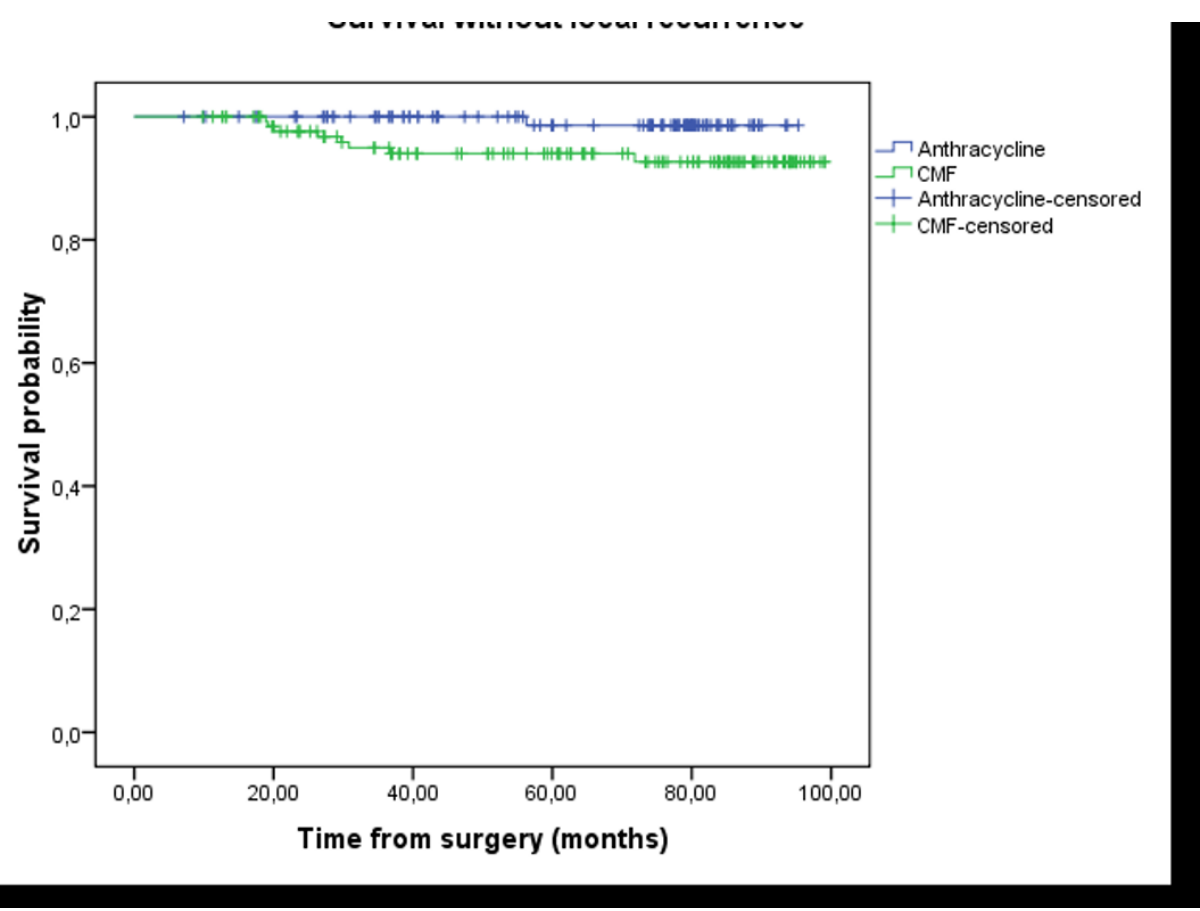

Figure I

Loco-regional-Free Survival (LRFS): the delay of LRFS was calculated by the date of surgery until the date of revealing of a loco-regional recurrence or until the date of death, or until the date of last news. The median follow-up, the rate of LRFS in five years, and the number of patients censored were presented. Group A (anthracycline): $\mathrm{N}=1 \mathrm{I} 0$ (I events, I09 censored); Group B (CMF): N = I34 (8 events, I26 censored); Survival probability at five years: $98.6 \%$ in group A vs $94 \%$ in group B; Logrank test: $p=0.033$.

\section{Figure 2}

Disease-Free Survival (DFS): the delay of DFS was calculated by the date of surgery until the date of revealing of a progress or until the date of death, or until the date of last news. The median follow-up, the rate of disease free survival in five years, and the number of patients censored were presented. Group A (anthracycline): N = II0 (2I events, 89 censored); Group B (CMF): $\mathrm{N}=134$ (36 events, 98 censored); Survival probability at five years: $80.4 \%$ in group A vs $76.4 \%$ in group B; Log-rank test: $p=$ 0.136. 


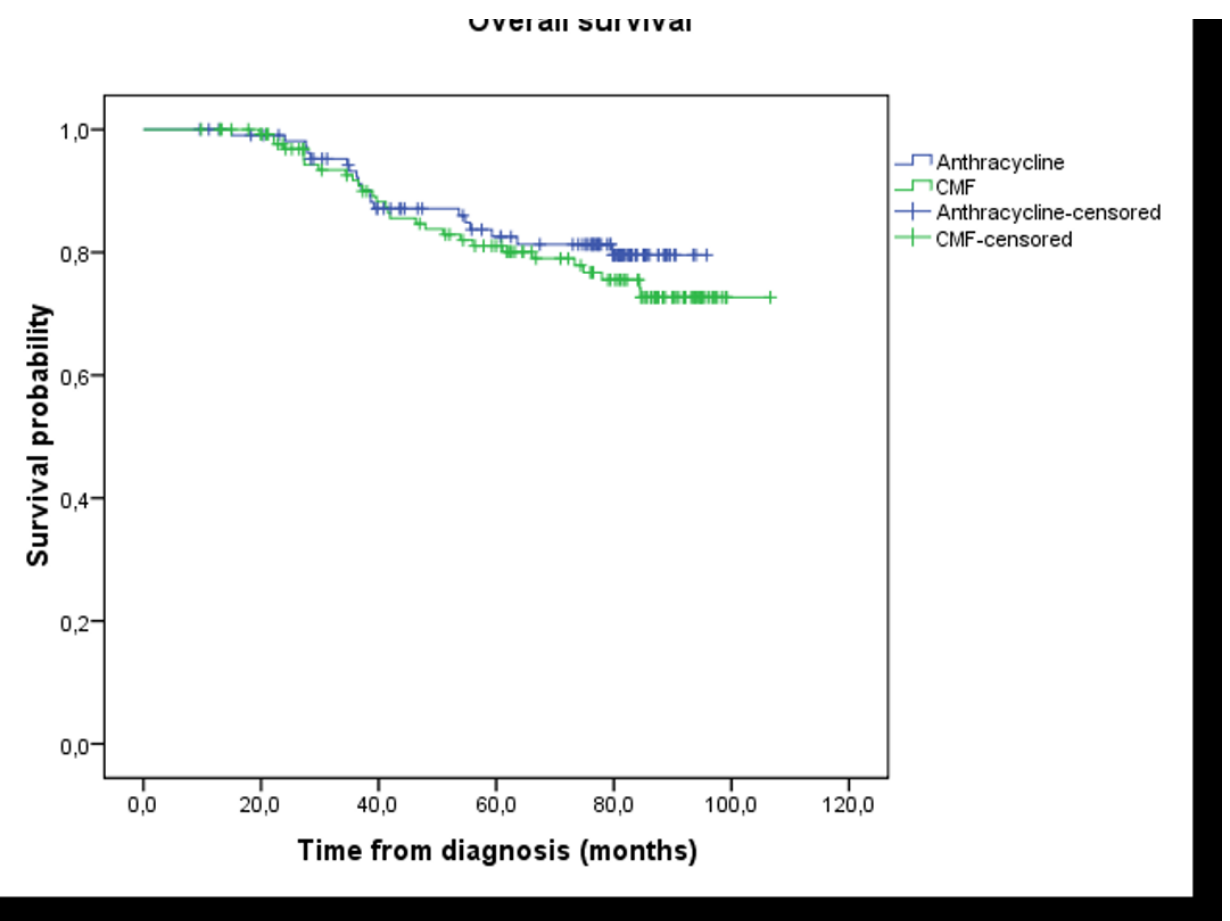

Figure 3

Overall survival (OS): the delay of OS was calculated by the date of histological diagnosis until the death or until the date of last news. The median follow-up, the rate of overall survival in five years, and the number of patients censored were presented. Group A (anthracycline): N = II 0 (19 events, 9I censored); Group B (CMF): N = I34 (29 events, I05 censored); Survival probability at five years: $82.5 \%$ in group $A$ vs $81.1 \%$ in group $B$; Log-rank test: $p=0.428$.

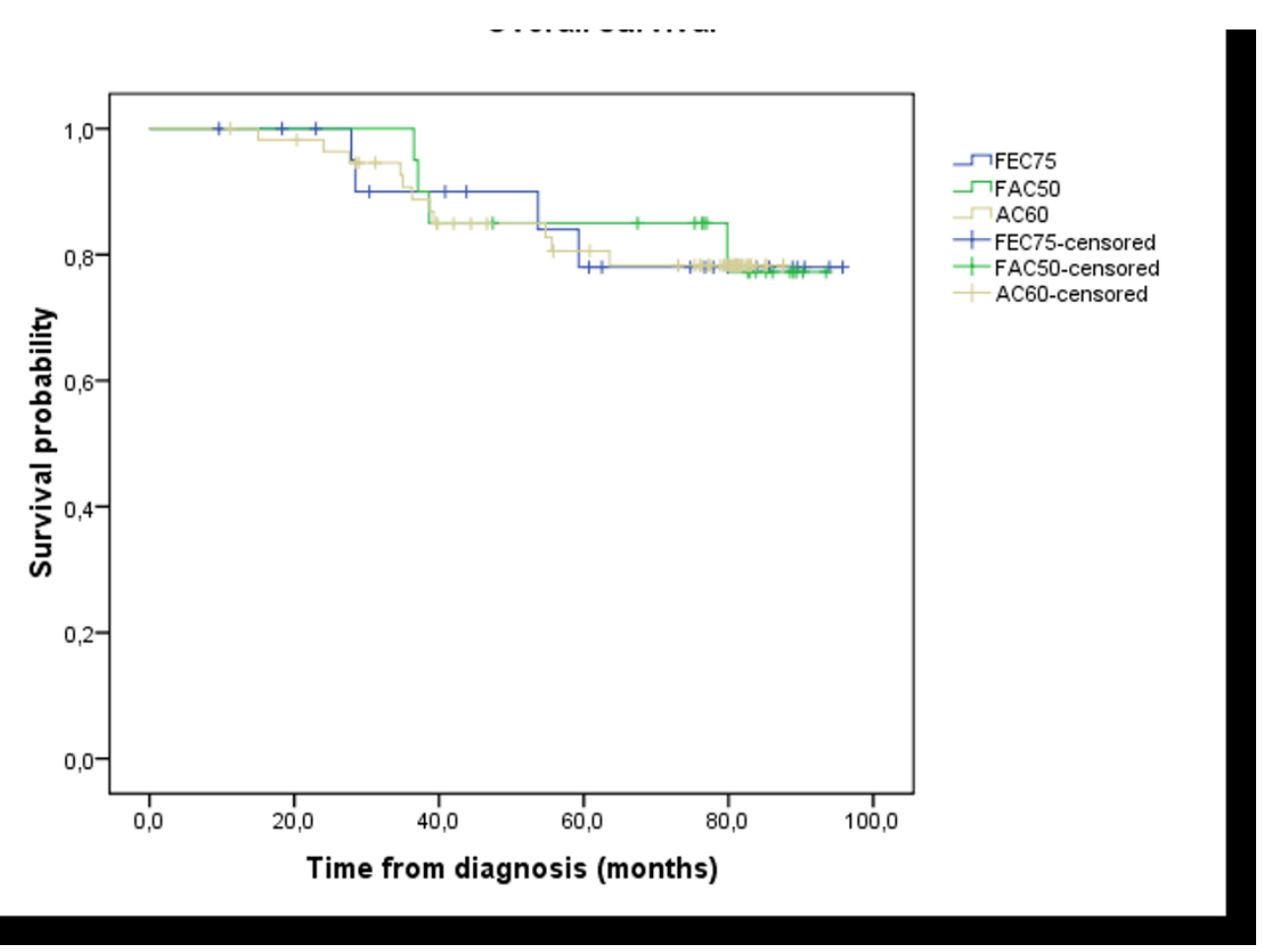

Figure 4

Overall survival (OS): difference between the three anthracycline sub-groups: AC60, FEC75, and FAC50; Log-rank test: $\mathrm{p}=$ 0.982 . 


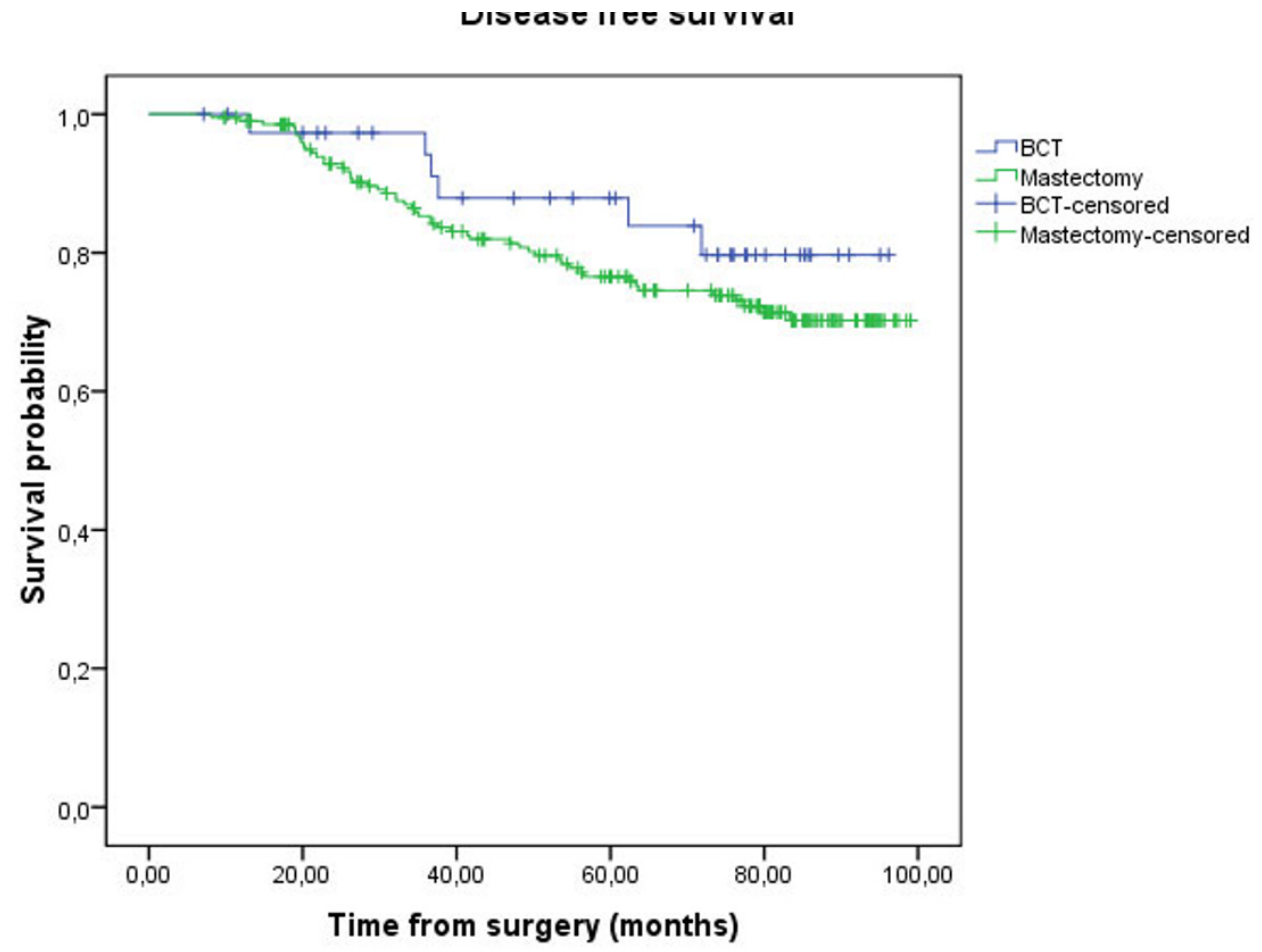

Figure 5

Disease-Free Survival (DFS): mastectomy compared to breast conservative therapy; Log-rank test: $p=0.288$.

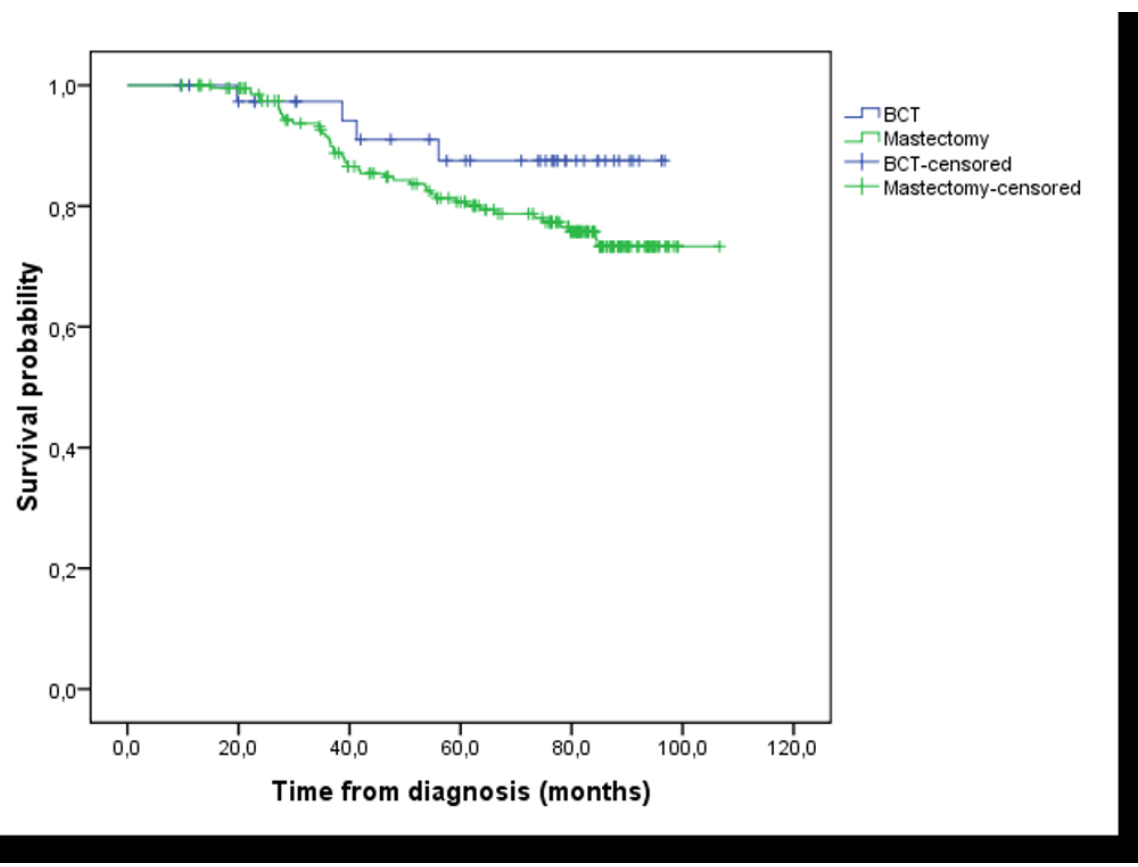

Figure 6

Overall survival (OS): mastectomy compared to breast conservative therapy; Log-rank test: $p=0.173$. 
Table 6: Univariate analysis of prognostic factors (Cox regression)

\begin{tabular}{ll}
\hline Factor & P value \\
\hline Age: $<40$ vs $\geq 40$ & 0.22 I \\
SBR: I vs SBR II-III & 0.402 \\
HR: positive vs negative & 0.675 \\
Tumour: PTI-2 vs PT3-4 & 0.263 \\
Lymph node involvement: yes vs no & 0.007 \\
Regimen: CMF vs Anthracycline & 0.428 \\
\hline
\end{tabular}

SBR = Scarf-Bloom-Richardson; HR = Hormonal receptors;

\section{Abbreviations}

CMF: cyclophosphamide $500 \mathrm{mg} / \mathrm{m}^{2}$, methotrexate 60 $\mathrm{mg} / \mathrm{m}^{2}$, and 5-fluorouracil $500 \mathrm{mg} / \mathrm{m}^{2} ;$ DFS: disease free survival; OS: overall survival; LRFS: loco-regional recurrence free survival; AC60: doxorubicin $60 \mathrm{mg} / \mathrm{m}^{2}$ and cyclophosphamide $600 \mathrm{mg} / \mathrm{m}^{2}$; FEC75: 5-fluorouracile $500 \mathrm{mg} / \mathrm{m}^{2}$, epirubicin $75 \mathrm{mg} / \mathrm{m}^{2}$, and cyclophosphamide $500 \mathrm{mg} / \mathrm{m}^{2}$; FAC50: 5-fluorouracile $500 \mathrm{mg} / \mathrm{m}^{2}$, doxorubicin $50 \mathrm{mg} / \mathrm{m}^{2}$, and cyclophosphamide $500 \mathrm{mg} /$ $\mathrm{m}^{2}$; BCT: breast conservative therapy; LVFE: left ventricular fraction ejection. FNC: 5-fluoro-uracil $500 \mathrm{mg} / \mathrm{m} 2$, mitoxantrone $12 \mathrm{mg} / \mathrm{m} 2$ and cyclophosphamide $500 \mathrm{mg} /$ $\mathrm{m} 2$.

\section{Competing interests}

The authors declare that they have no competing interests.

\section{Authors' contributions}

NI: conception and design, acquisition of data, analysis and interpretation of data, statistical analysis, literature review, drafting the manuscript and revising it critically for important intellectual content; NM: acquisition and analysis of data; OM: acquisition and analysis of data; SE: acquisition and analysis of data; SA: acquisition and analysis of data; IB: acquisition and analysis of data; SA: acquisition and analysis of data; ZB: drafting the discussion; MAT: statistical analysis; AE: acquisition of data; OE: review of finale manuscript; $\mathrm{NB}$ : review of finale manuscript; BEKEG: review of finale manuscript; $\mathrm{MI}$ : involved in drafting the manuscript and revising it critically for important intellectual content; SA: statistical analysis; HE: conception, design and review of final manuscript.

\section{Additional material}

\section{Additional file 1}

Diagram. Diagram to summarize therapeutic strategy.

Click here for file

[http://www.biomedcentral.com/content/supplementary/1748-

717X-4-12-S1.doc]

\section{Acknowledgements}

We acknowledge the help of the Department of Medical Oncology, National Institute of Oncology, Rabat, especially Bahri Hicham.

\section{References}

I. Pierce LJ, Lichter AS: Defining the role of post-mastectomy radiotherapy: The new evidence. Oncology (Williston Park) 1996, 10:991-1002.

2. Fowble B: Postmastectomy radiotherapy: Then and now. Oncology (Williston Park) 1997, I I :2 I 3-239.

3. Overgaard M, Hansen PS, Overgaard J, Rose C, Andersson M, Bach F, et al.: Postoperative radiotherapy in high-risk premenopausal women with breast cancer who receive adjuvant chemotherapy. N Engl J Med 1997, 337:949-955.

4. Overgaard M, Jensen MB, Overgaard J, Hansen PS, Rose C, Andersson $M$, et al: Postoperative radiotherapy in high-risk postmenopausal breast-cancer patients given adjuvant tamoxifen: Danish Breast Cancer Cooperative Group DBCG 82c randomized trial. Lancet 1999, 353:1641-1648.

5. Ragaz J, Olivotto I, Spinelli JJ, Phillips N, Jackson SM, Wilson KS, et al.: Locoregional radiation therapy in patients with high-risk breast cancer receiving adjuvant chemotherapy: 20-year results of the British Columbia randomized trial. J Natl Cancer Inst 2005, 97: I 16-126.

6. Early Breast Cancer Trialists' Collaborative Group: Effects of radiotherapy and surgery in early breast cancer: An overview of the randomized trials. N Engl J Med I995, 333:|444-I455.

7. Early Breast Cancer Trialists' Collaborative Group: Favourable and unfavourable effects on long-term survival of radiotherapy for early breast cancer: An overview of the randomized trials. Lancet 2000, 355: I757-I770.

8. Veronesi U, Marubini E, Mariani L, Galimberti V, Veronesi P, Salvadori $B$, et al.: Radiotherapy after breast-conserving surgery in small breast carcinoma: Longterm results of a randomized trial. Ann Oncol 200I, I 2:997-1003.

9. Fisher B, Anderson S, Bryant J, Magolese RG, Deutch M, Fisher ER, et al.: Twenty-years follow- up of a randomized trial comparing total mastectomy, lumpectomy, and lumpectomy plus irradiation for the treatment of invasive breast cancer. $N$ Engl J Med 2002, 347:|233-|24I.

10. Fisher B, Carbone P, Economou SG, Frelick R, Glass A, Lemer H, et al.: Phenylalanine mustard (L- PAM) in the management of primary breast cancer: a report of early findings. N Engl J Med 1975, 292: II7.

II. Bonadonna G, Brusamolino E, Valagussa P, Rossi A, Brugnatelli L, Brambilla $C$, et al:: Combination chemotherapy as an adjuvant treatment in operable breast cancer. $N$ Engl J Med 1976, 294:405-410.

12. Early Breast Cancer Trialists' Collaborative Group. Systemic treatment of early breast cancer by hormonal cytotoxic, or immune therapy: 133 randomized trials involving 31,000 recurrences and 24,000 deaths along 75,000 women. Lancet 1992, 339: I- I5. 71-84.

13. Hartsell WF, Recine DC, Griem KL, Muthy AK: Delaying the initiation of intact breast irradiation for patients with lymph node positive breast cancer increases the risk of local recurrence. Cancer 1995, 76:2497-2503.

14. Buchholz TA, Austin-Seymour MM, Moe RE, Ellis GK, Livingston RB, Pelton JG, et al.: Effect of delay in radiation in the combined modality treatment of breast cancer. Int J Radiat Oncol Biol Phys 1993, 26:23-35.

15. Greene FL, Page DL, Fleming ID: AJCC cancer staging manual. 6th edition. New York: Springer-Verglag; 2002.

16. Recht A, Come SE, Gelman RS, Goldtein M, Tishler S, Gore SM, et al.: Integration of conservative surgery, radiotherapy and chemotherapy for the treatment of early-stage, node-positive breast cancer: Sequencing, timing, and outcome. J Clin Oncol 1991, 9:1662-1667.

17. Recht A, Come SE, Henderson IC, Gelman RS, Silver B, Hayes DF, et al.: The sequencing of chemotherapy and radiation therapy after conservative surgery for early-stage breast cancer. $N$ Engl I Med 1996, 334:1356-1361. 
18. Vujovic O, Perera F, Dar AR, Stitt L, Yu E, Voruganti SM, et al.: Does delay in breast irradiation following conservative breast surgery in nodenegative cancer patients have an impact on risk of recurrence? Int J Radiat Oncol Biol Phys 1998, 40:869-874.

19. Buchholz TA, Hunt KK, Amoss CM, Tucker SL, Strom EA, McNeese $M D$, et al.: Sequencing of chemotherapy and radiation in lymph node-negative breast cancer. Cancer J Sci Am 1999, 5:159-164.

20. Leonard CE, Wood ME, Zhen B, Rankin J, Waitz DA, Notron L, et al.: Does administration of chemotherapy before radiotherapy in breast cancer patients treated with conservative surgery negatively impact local control? I Clin Oncol 1995, 13:2906-29I5.

21. Kouloulias VE, Dardoufas CE, Kouvaris JR, Gennatas CS, Polyzos AK Gogas HJ, Sandilos PH, Uzunoglu NK, Malas EG, Vlahos LJ: Liposomal doxorubicin in conjunction with reirradiation and local hyperthermia treatment in recurrent breast cancer: a phase I/II trial. Clin Cancer Res 2002, 8(2):374-82.

22. Kao J, Conzen SD, Jaskowiak NT, Song DH, Recant W, Singh R, Masters GA, Fleming GF, Heimann R: Concomitant radiation therapy and paclitaxel for unresectable locally advanced breast cancer: results from two consecutive phase I/II trials. Int J Radiat Oncol Biol Phys 2005, 6 I (4): 1045-53.

23. Würschmidt F, Dahle J, Petersen C, Wenzel C, Kretschmer M, Bastian C: Reirradiation of recurrent breast cancer with and without concurrent chemotherapy. Radiat Oncol 2008, 3:28.

24. Toledano A, Azria D, Garaud P, Fouquet A, Serin D, Bosset JF, et al.: Phase III trial of concurrent or sequential adjuvant chemoradiotherapy after conservative surgery for early-stage breast cancer: Final results of the ARCOSEIN trial. J Clin Oncol 2007, 25(4):405-10.

25. Arcangeli G, Pinnaro P, Rambone R, Giannarelli D, Benassi M, et al:: A phase III randomized study on the sequence of radiotherapy and chemotherapy in the conservative management of early-stage breast cancer. Int J Radiat Oncol Biol Phys 2006, 64:16I-167.

26. Rouessé J, De la Lande B, Bertheault-Cvitkovic F, Serin D, Graic $Y$, Combe $M$, et al:: A phase III randomized trial comparing adjuvant concomitant chemoradiotherapy versus standard adjuvant chemotherapy followed by radiotherapy in operable node-positive breast cancer: Final results. Int J Radiat Oncol Biol Phys 2006, 64: 1072-1080.

Publish with Bio Med Central and every scientist can read your work free of charge

"BioMed Central will be the most significant development for disseminating the results of biomedical research in our lifetime. "

Sir Paul Nurse, Cancer Research UK

Your research papers will be:

- available free of charge to the entire biomedical community

- peer reviewed and published immediately upon acceptance

- cited in PubMed and archived on PubMed Central

- yours - you keep the copyright

Submit your manuscript here:

http://www.biomedcentral.com/info/publishing_adv.asp
BioMedcentral 